\title{
Using Mustard Oil as Ecological Additive to Petroleum Diesel Fuel
}

\author{
V.A. Markov \\ Department «Piston Engines» \\ Bauman Moscow State Technical University \\ Moscow, Russia \\ vladimir.markov58@yandex.ru
}

\author{
V.G. Kamaltdinov \\ Department «Internal Combustion Engines and Electronic \\ Systems of Cars» \\ South Ural State University \\ Chelyabinsk, Russia \\ vkamaltdinov@yandex.ru
}

\author{
S.S. Loboda \\ Department «Piston Engines» \\ Bauman Moscow State Technical University \\ Moscow, Russia \\ st-loboda@yandex.ru
}

\begin{abstract}
The relevance of the article is due to the need for wider use of the alternative fuels in internal combustion engines. Advantages of using fuels of vegetable origin as motor fuels are shown. Experimental research of diesel engine D-245.12S functioning on mixtures of diesel fuel and mustard oil of various percentage is given. Possible ways of using mustard oil as fuel for a diesel engine are considered. An opportunity of improving characteristics of exhaust gases toxicity by using these mixtures as a fuel for automobile and tractor diesel engines is demonstrated.
\end{abstract}

Key words - diesel engine, petroleum diesel fuel, alternative fuel, vegetable oil, rapeseed oil, mustard oil, biofuel mixture

\section{[1] THE FOUNDATION OF MUSTARD OIL USAGE AS AN OXYGEN-CONTAINING ADDITIVE TO PETROLEUM DIESEL FUEL}

Among alternative motor fuels, the most attractive fuels are those made of renewable raw sources - biofuel of vegetable origin [1, 2]. As a perspective energy source in motor-and-tractor diesels, the fuel from vegetable oil is considered [3, 4]. This is determined by renewability of its raw, simplicity and ecological compatibility of vegetative oil manufacture, relatively low cost and acceptable inflammability within a diesel combustion chamber (CC). At that, using the mixtures of petroleum diesel fuel with little vegetable oil addition is the most reasonable. So, the diesel operation on the above-mentioned fuels is possible with no significant constructive changes in engines and their systems.

The addition of vegetable oil to diesel fuel noticeably reduces the toxicity of exhaust. Herewith, the possibility to lower the emission of carbon dioxide into atmosphere appears. The emission of critical toxic components includes nitrogen oxides $\mathrm{NO}_{\mathrm{x}}$, carbon monoxide $\mathrm{CO}$, light unburned hydrocarbons $\mathrm{CH}_{\mathrm{x}}$, soot (also - exhaust capacity). This is determined by a significant content of oxygen atoms in vegetable oil molecules, which amounts to $10-12 \%$ in mass. In this case, the vegetable oil is used as an oxygen-containing additive (oxidant).

The oilseeds serve as the source of vegetable oil, wherein different parts - seeds or fruits - contain vegetable fats. At present, European countries primarily use raps for biofuel generation [5-7]. The most significant vegetable oil in Russia is sunflower oil $(86.84 \%)$. Then soybean oil $(7.96 \%)$, raps oil $(4.84 \%)$, mustard oil $(0.11 \%)$, corn oil $(0.04 \%)$ and linen oil $(0.03 \%)$ follow.

The mustard is a plant of crucifirae that include such wellknown rural cultures as cabbage, radish, turnip, horseradish, raps, saffron milk cap etc. Mustard oil is obtained from mustard seeds by the compacting method or seed extraction. One should notice that physicochemical properties of mustard oil depend on the sort of oil culture, conditions of breeding and treatment technology.

\section{[2] THE RESEARCH OF DIESEL, RUNNING ON PETROLEUM DIESEL FUEL AND MUSTARD OIL MIXTURES}

There are works in evaluation of mustard oil (MO) as a main fuel or as an additive to petroleum diesel fuel (DF) [8, 9, 10]. Alongside, the problem of choosing the optimal MO content as an additive to DF is still unexplored. To evaluate the possibility of using $\mathrm{MO}$ as an ecological additive to petroleum diesel fuel and to determine its optimal content, some experimental data of research with diesel engine D245.12S (4 ChN 11/12,5) of Minsk Motor Plant (MMZ), set on light commercial trucks ZIL-5301, Pavlovsk Motor Plant (PAZ) and tractors «Belarus», are referred to. 
Table I. Physically-chemical properties of investigated fuels

\begin{tabular}{|c|c|c|c|c|c|}
\hline \multirow[t]{2}{*}{ Physically-chemical properties } & \multicolumn{5}{|c|}{ Fuel } \\
\hline & $\overline{D F}$ & RO & MO & $95 \% \mathrm{DF}+5 \% \mathrm{MO}$ & $90 \% \mathrm{DF}+10 \% \mathrm{MO}$ \\
\hline Density $\left(20^{\circ} \mathrm{C}\right), \mathrm{kg} / \mathrm{m}^{3}$ & 830.0 & 916.0 & 920.0 & 835.0 & 839.0 \\
\hline Kinematic viscosity $\left(20^{\circ} \mathrm{C}\right), \mathrm{mm}^{2} / \mathrm{s}$ & 3.8 & 75.0 & 70.0 & 5.0 & 7.0 \\
\hline Surface tension ratio $\left(20^{\circ} \mathrm{C}\right), \mathrm{mN} / \mathrm{m}$ & 27.1 & 33.2 & 33.1 & - & - \\
\hline Least combustion heating, $\mathrm{kJ} / \mathrm{kg}$ & 42500 & 37300 & 37200 & 42100 & 41900 \\
\hline Cetane number & 45 & 36 & 35 & - & - \\
\hline Self-Flammability point, ${ }^{\circ} \mathrm{C}$ & 250 & 318 & 320 & - & - \\
\hline Clouding point, ${ }^{\circ} \mathrm{C}$ & -25 & -9 & -8 & - & - \\
\hline Solidification point, ${ }^{\circ} \mathrm{C}$ & -35 & -20 & -18 & - & - \\
\hline Air quantity for combustion of $1 \mathrm{~kg}$ of fuel, $\mathrm{kg}$ & 14.31 & 12.50 & 12.44 & 14.19 & 14.11 \\
\hline Content, \% in mass & $\begin{array}{c}87.0 \\
12.6 \\
0.4\end{array}$ & $\begin{array}{l}77.0 \\
12.0 \\
11.0\end{array}$ & $\begin{array}{l}77.1 \\
11.8 \\
11.1\end{array}$ & $\begin{array}{c}86.5 \\
12.5 \\
1.0\end{array}$ & $\begin{array}{c}86.0 \\
12.5 \\
1.5\end{array}$ \\
\hline Common sulfur content, $\%$ in mass & 0.20 & 0.002 & 0.002 & 0.190 & 0.180 \\
\hline
\end{tabular}

Table II. The values of diesel engine D-245.12S running on petroleum diesel fuel and its mixtures with mustard oil

\begin{tabular}{|c|c|c|c|}
\hline \multirow[t]{2}{*}{ Indicators } & \multicolumn{3}{|c|}{ Fuel } \\
\hline & $\overline{\text { DF }}$ & $95 \% \mathrm{DF}+5 \% \mathrm{MO}$ & $90 \%$ DF + 10\% MO \\
\hline $\begin{array}{l}\text { Fuel consumption per hour } G_{t}, \mathrm{~kg} / \mathrm{h} \text { : } \\
\text { - in maximum capacity mode } \\
\text { - in maximum torque mode }\end{array}$ & $\begin{array}{l}20.10 \\
13.00\end{array}$ & $\begin{array}{l}20.17 \\
13.13\end{array}$ & $\begin{array}{l}20.25 \\
13.22\end{array}$ \\
\hline $\begin{array}{l}\text { Torque } M_{e}, \mathrm{~N} \cdot \mathrm{m}: \\
\text { - in maximum capacity mode } \\
\text { - in maximum torque mode }\end{array}$ & $\begin{array}{l}321 \\
364\end{array}$ & $\begin{array}{l}321 \\
366\end{array}$ & $\begin{array}{l}318 \\
363\end{array}$ \\
\hline $\begin{array}{l}\text { Fuel specific consumption } g_{e}, \mathrm{~g} /(\mathrm{kW} \cdot \mathrm{h}) \text { : } \\
\text { - in maximum capacity mode } \\
\text { - in maximum torque mode }\end{array}$ & $\begin{array}{l}248.2 \\
226.2 \\
\end{array}$ & $\begin{array}{l}250.1 \\
228.9 \\
\end{array}$ & $\begin{array}{l}253.4 \\
231.9 \\
\end{array}$ \\
\hline $\begin{array}{l}\text { Energy efficiency } \eta_{e}: \\
\text { - in maximum capacity mode } \\
\text { - in maximum torque mode }\end{array}$ & $\begin{array}{l}0.341 \\
0.374\end{array}$ & $\begin{array}{l}0.341 \\
0.373\end{array}$ & $\begin{array}{l}0.339 \\
0.370\end{array}$ \\
\hline $\begin{array}{l}\text { Exhaust smokiness } K x, \% \text { in Hartidge scale: } \\
\text { - in maximum capacity mode } \\
\text { - in maximum torque mode }\end{array}$ & $\begin{array}{l}17 \\
42 \\
\end{array}$ & $\begin{array}{l}15 \\
38 \\
\end{array}$ & $\begin{array}{l}12 \\
36 \\
\end{array}$ \\
\hline $\begin{array}{l}\text { Conditional fuel economy values in } 13 \text {-stage cycle modes: } \\
\text { - fuel specific consumption } g_{e} \text { con }, \mathrm{g} /(\mathrm{kW} \cdot \mathrm{h}) \\
\text { - energy efficiency } \eta_{e \text { con }}\end{array}$ & $\begin{array}{c}244.63 \\
0.346 \\
\end{array}$ & $\begin{array}{c}247.17 \\
0.346 \\
\end{array}$ & $\begin{array}{c}251.08 \\
0.342 \\
\end{array}$ \\
\hline $\begin{array}{l}\text { Integral specific mass emissions in 13-stage cycle modes, } \mathrm{g} /(\mathrm{kW} \cdot \mathrm{h}) \text { : } \\
-e_{\mathrm{NOx}} \\
-e_{\mathrm{CO}} \\
-e_{\mathrm{CHx}}\end{array}$ & $\begin{array}{l}5.911 \\
2.184 \\
0.675\end{array}$ & $\begin{array}{l}5.760 \\
2.140 \\
0.602\end{array}$ & $\begin{array}{l}5.689 \\
2.068 \\
0.561\end{array}$ \\
\hline
\end{tabular}

During the experimental research, the exhaust toxicity and fuel economy analysis of diesel, running on DF of «L» type (acc. to GOST 305-82) and DF+MO mixture, was carried out. Some physicochemical properties of investigated fuels are referred in Table 1. In this table, the properties of raps oil, investigated in works 1,2 , are also referred to. The diesel was explored on a motor stand on $\mathrm{VSH}$ and at 13-stage (Regulations 49 EEC UN) modes with set pre-injection $\theta=13^{\circ}$ of the crankshaft before TDC and fixed rail position of fuel supply (maximal fuel supply).

At the first stage of research, the test of diesel engine D$245.12 \mathrm{C}$ running on pure DF and $90 \% \mathrm{DF}+10 \% \mathrm{MO}$ mixtures at maximal fuel supply was carried out. The results of this test are presented in Fig. 1 and Table 2. At the second stage of research, the diesel was operating at 13-stage cycle ECE R49. The results of these experiments with diesel D- 
245.12S are presented in Fig. 2. With a $90 \% \mathrm{DF}+10 \% \mathrm{MO}$ mixture, using the tendency of $\mathrm{NO}_{\mathrm{x}}, \mathrm{CO}$ and $\mathrm{CH}_{\mathrm{x}}$, the reduction in the exhaust was observed. The similar test with diesel engine D-245.12S, running on the $95 \% \mathrm{DF}+5 \% \mathrm{MO}$ mixture, was carried out.

According to the obtained data, the content of toxic components $\left(\mathrm{NO}_{\mathrm{x}}, \mathrm{CO}, \mathrm{CH}_{\mathrm{x}}\right)$ in exhaust was determined by common methods, as well as their integral mass emissions in 13 -stage cycle ECE R49 ( $e_{\mathrm{NOx}}, e_{\mathrm{CO}}, e_{\mathrm{CHx}}$ accordingly). At that, the concentration of toxic components $\left(C_{\mathrm{NOx}}, C_{\mathrm{CO}}, C_{\mathrm{CHx}}\right)$ for each mode was determined and their hourly mass emissions $\left(E_{\mathrm{NOx}}, E_{\mathrm{CO}}, E_{\mathrm{CHx}}\right)$ were calculated. The obtained values of harmful emissions by each component were summarized for the whole cycle (considering weight coefficients $K_{i}$ ). Then, dividing by conditional mean power for testing cycle $\Sigma\left(N_{e i} \cdot K_{i}\right)$, the specific harmful emissions were determined by [3-5] as:

$$
\begin{gathered}
e_{\mathrm{NOx}}=\frac{\sum_{i=1}^{13} E_{\mathrm{NOx} i} \cdot K_{i}}{\sum_{i=1}^{13} N_{e i} \cdot K_{i}}, \quad e_{\mathrm{CO}}=\frac{\sum_{i=1}^{13} E_{\mathrm{CO} i} \cdot K_{i}}{\sum_{i=1}^{13} N_{e i} \cdot K_{i}}, \\
e_{\mathrm{CHx}}=\frac{\sum_{i=1}^{13} E_{\mathrm{CHx} i} \cdot K_{i}}{\sum_{i=1}^{13} N_{e i} \cdot K_{i}} .
\end{gathered}
$$

The evaluation of fuel consumption by modes of the 13stage cycle was carried out by average (conditional) break specific fuel consumption, which was determined by [3-5] as:

$$
g_{e \mathrm{con}}=\frac{\sum_{i=1}^{13} G_{\mathrm{T} i} \cdot K_{i}}{\sum_{i=1}^{13} N_{e i} \cdot K_{i}}
$$

where $G_{\mathrm{T} i}$ and $N_{e i}$ - hourly fuel consumption and effective power output of engine in $i$-th mode; $K_{i}$ - weight coefficient of the mode (the share of mode time). Fuel economy of diesel, running on researched fuels, was estimated by not only break specific fuel consumption $g_{e}$, but also by efficiency coefficient $\eta_{e}$

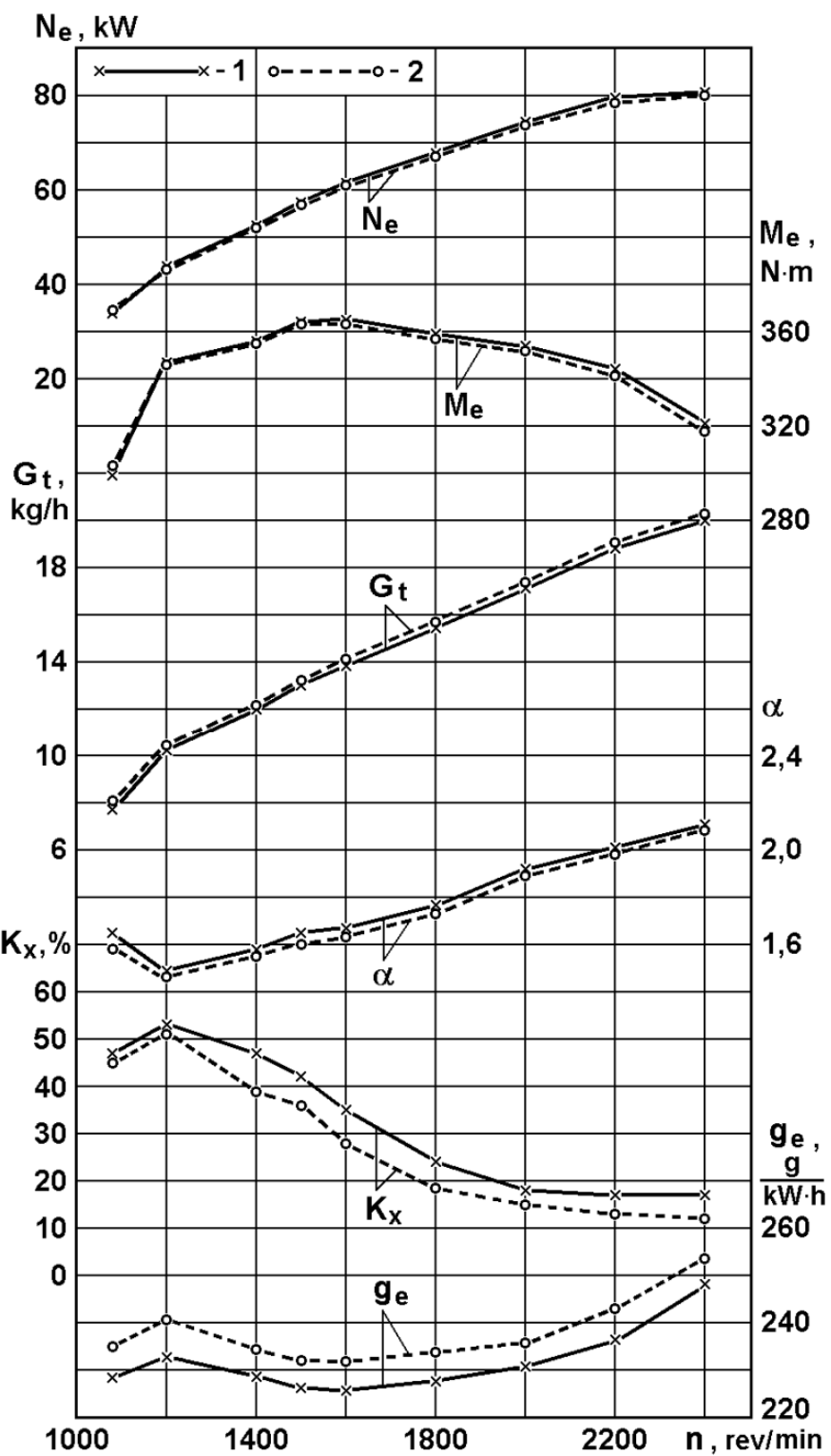

Fig. 1. Relation of capacity $N_{e}$, torque $M_{e}$, fuel consumption per hour $G_{\mathrm{t}}$, air excess ratio $\alpha$, exhaust smokiness $K x$ and specific fuel consumption $g_{e}$ with RPM $n$ of diesel engine D-245.12S for mixtures with different diesel fuel; mustard oil ratios: 1 - 100:0; 2 - 90:10

Besides, to estimate integrally the diesel operation in 13-stage cycle modes, the conditional efficiency coefficient was used, which was determined as:

$$
\eta_{e \mathrm{con}}=\frac{3600}{H_{U} \cdot g_{e \mathrm{con}}}
$$

where $H_{U}$ - lower heating value of the fuel, $\mathrm{MJ} / \mathrm{kg}$. The results of calculations are referred to in Table 2 and Fig. 3. 


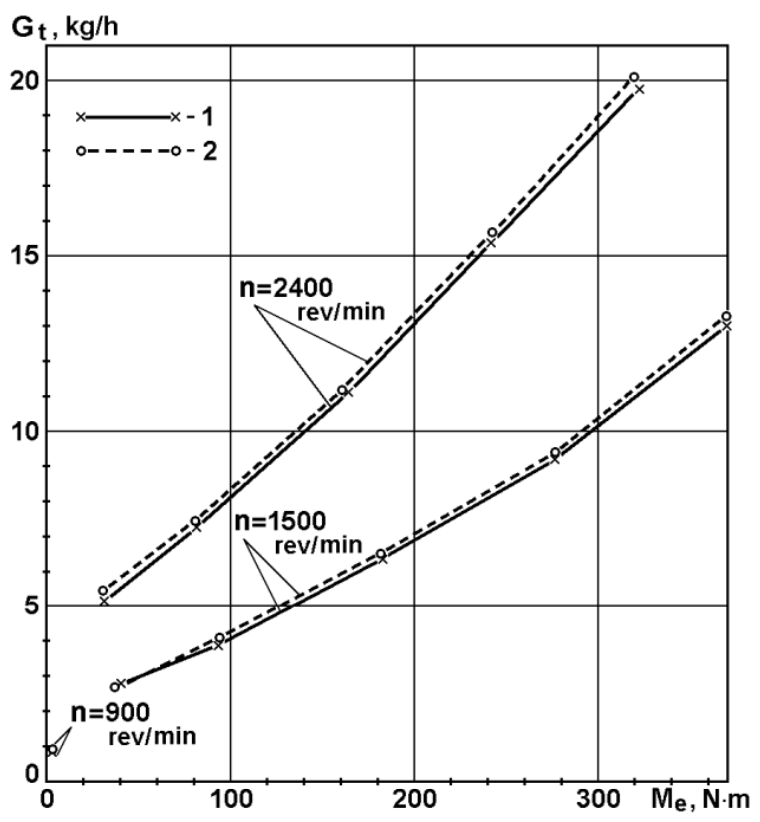

a

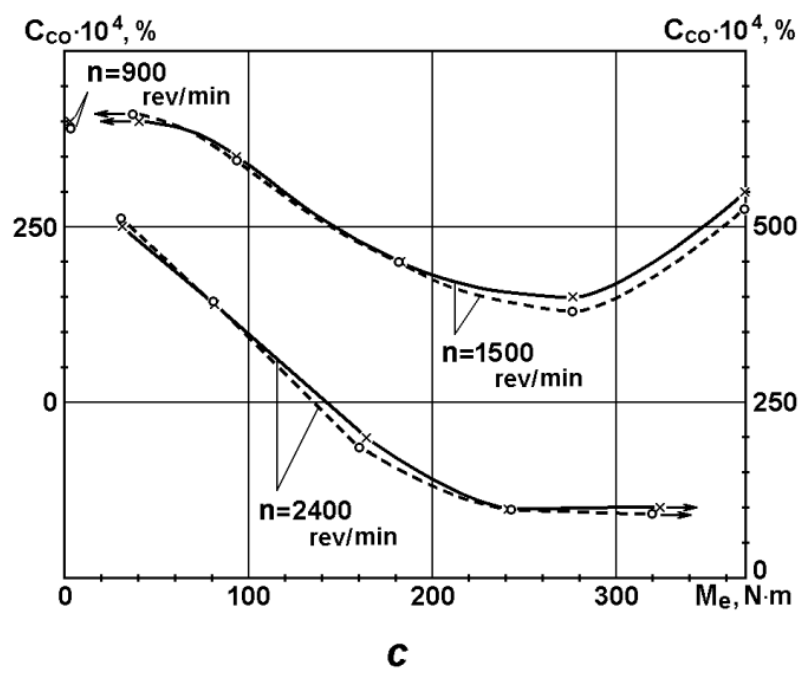

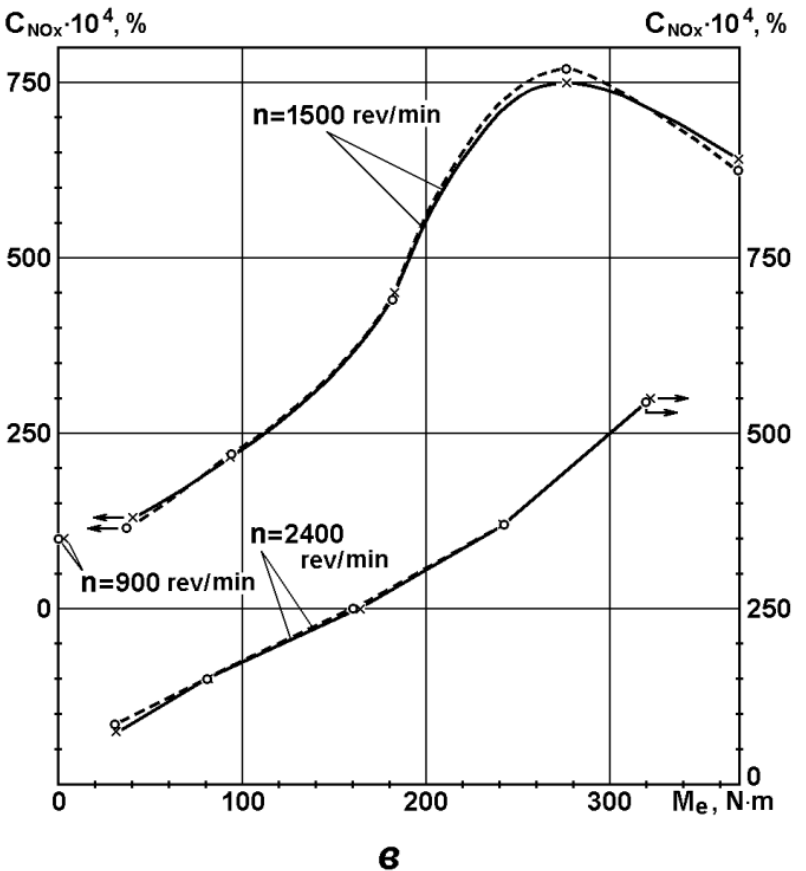

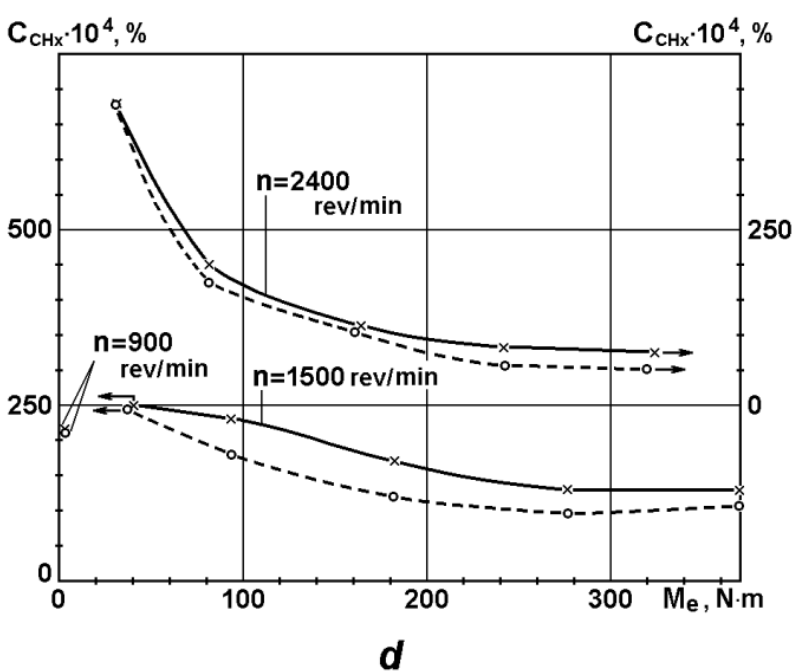

Fig 2. Hourly fuel consumption $G_{\mathrm{r}}(a)$, volume concentration of nitrogen oxides in exhaust $C_{\mathrm{NOx}}(b)$, carbon monoxide $C_{\mathrm{CO}}(c)$ and unburned hydrocarbons $C_{\mathrm{CHx}}$ (d) as RPM function of $n$ and torque $M_{e}$ of diesel engine D-245.12S running on fuels: $1-\mathrm{DF} ; 2-90 \% \mathrm{DF}+10 \% \mathrm{MO}$ 

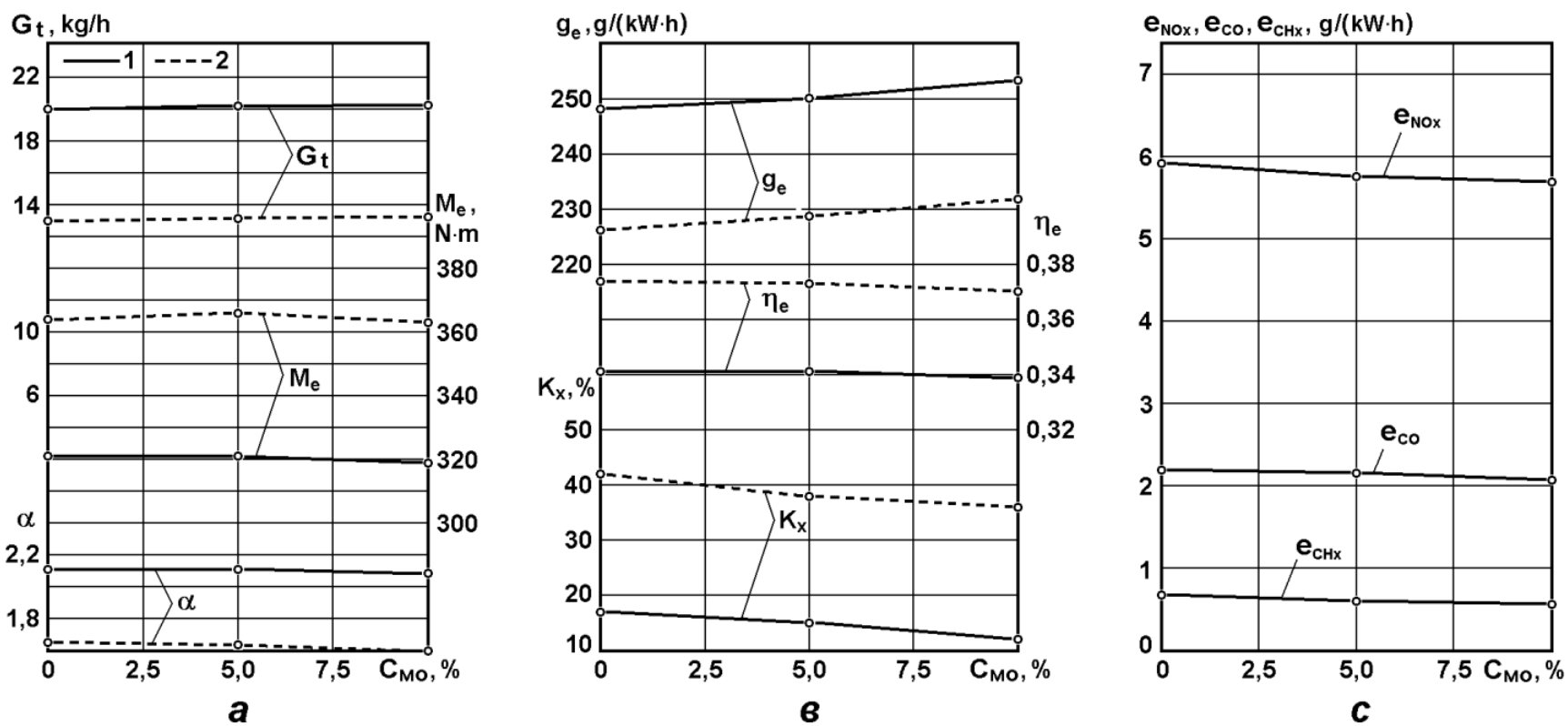

Fig. 3. Hourly fuel consumption $G_{\mathrm{T}}$, torque $M_{e}$ and air-fuel ratio $\alpha(a)$, break specific fuel consumption $g_{e}$, efficiency coefficient $\eta_{e}$, exhaust smoke opacity $K_{\mathrm{X}}(b)$, specific mass emissions of nitrogen oxides $e_{\mathrm{NOx}}$, carbon monoxide $e_{\mathrm{CO}}$, unburned hydrocarbons $e_{\mathrm{CHx}}$ on full-load curve (c) of diesel engine D-245.12S as function of mustard oil content in mixed biofuel $C_{\mathrm{MO}}: 1$ - in maximum capacity mode; 2 - in maximum torque mode.

Data, referred to in Table 2 and Fig. 3, confirm the possibility of improving ecological indicators of diesel D$245.12 \mathrm{~S}$ with transition from DF to researched mixtures. Such improvement of ecological parameters with $\mathrm{DF}+\mathrm{MO}$ mixtures was obtained without changes in constructive and regulating parameters of the diesel. To achieve a bigger reduction in toxic components emission and to improve the indicators of diesel fuel economy during adaptation, the construction improvements of the biofuel engine are needed. In particular, it is advantageous to refine the flowing part of nozzles for the reduction of fuel squirt length and to adjust the nozzles with the shape of the combustion chamber, as well as to specify the regulating parameters of diesel (first - to specify the pre-injection and vary it with changes in fuel properties). The other way of improvements in diesel indicators with DF + MO mixtures is optimization of the mixture composition.

\section{[3] CONCLUSION}

1. Referred investigations confirmed the efficiency of DF + MO mixtures in domestic diesels and the possibility of enhancing the exhaust toxicity indicators along with mixed biofuel.

2. If running in 13-stage cycle (№49 EEC UN) modes on mixed biofuel $90 \% \mathrm{DF}+10 \mathrm{MO}$ instead of petroleum diesel fuel, the diesel features reduced emissions of nitrogen oxides $e_{\mathrm{NOx}}$ from 5,911 to $5,689 \mathrm{~g} /(\mathrm{kW} \cdot \mathrm{h})$, carbon monoxide $e_{\mathrm{CO}}-$ from 2,184 to $2,068 \mathrm{~g} /(\mathrm{kW} \cdot \mathrm{h})$, unburned hydrocarbons $e_{\mathrm{CHx}}-$ from 0,675 to $0,561 \mathrm{~g} /(\mathrm{kW} \cdot \mathrm{h})$.

3. If running on a full-load curve on mixed biofuel $90 \% \mathrm{DF}+$ $10 \%$ MO instead of petroleum diesel fuel, the diesel features smoke opacity $K_{\mathrm{X}}$ reduced from 17 to $12 \%$ in a maximal power mode $\left(n=2400 \mathrm{~min}^{-1}\right)$, and from 42 to $36 \%$ - in a maximal torque mode $\left(n=1500 \mathrm{~min}^{-1}\right)$ on Hartridge scale.

\section{References}

[1] A.A. Aleksandrov, I.A. Arkharov, S.N. Devyanin, V.A. Markov, Alternative Fuels for Internal Combustion Engines, LLC Scientific Research Centre Engineer Publ., LLC OnikoM Publ., Moscow, 2012.

[2] V. L'otko, V.N. Lukanin, A.S. Khachijan, Utilization of Alternative Fuels in Internal Combustion Engines, Publ. of «MADI (TU)», Moscow, 2000.

[3] V.A. Markov, S.N. Devyanin, V.G. Semenov, V.V. Bagrov, Using Vegetable Oils and Vegetable Oils Based Fuels in Diesel Engines, LLC Scientific Research Centre Engineer, LLC OnikoM Publ., Moscow, 2011.

[4] V.A. Markov, S.N. Devyanin, S.A. Zykov, S.M. Gajdar, Biofuels for internal combustion engines, LLC Scientific Research Centre Engineer Publ., Moscow, 292 p.

[5] V.A. Markov, R.M. Bashirov, I.I. Gabitov, Toxicity of Diesel Exhaust Gases, Publ. of Bauman Moscow State University, Moscow, 2002.

[6] M. Hashimoto, T. Dan, I. Asano, T. Arakawa, Combustion of the RapeSeed Oil in a Diesel Engine, SAE Technical Paper Series, 2002-01-0867, pp. 1-12, 2002.

[7] B.M. Spessert, A. Schleicher, Einfluss von Biokraftstoffen auf die Abgasund Gerauschemission kleiner Industriedieselmotoren, MTZ, №3, 212221, 2007.

[8] S.A. Niemi, P.E. Illikanen, V.O.K. Laiho, A Tractor Engine Fueled with Mustard Seed Oil: Optimization, Emissions and Practical Experiences, SAE Technical Paper Series, 972724, 1997, pp. 11-25. 
[9] S.A. Niemi, T. Hatonen, V.O.K. Laiho, Results from a Durability Test of a Mustard Seed Oil Driven Tractor Engine, SAE Technical Paper Series, 982528, pp. 1-15, 1998.

[10] S.A. Niemi, T.T. Murtonen, M.J. Lauren, V.O.K. Laiho, Exhaust Particulate Emissions of a Mustard Seed Oil Driven Tractor Engine, SAE Technical Paper Series, 2002-01-0866, pp. 1-12, 2002. 